This is a post-peer-review, pre-copy edited version of an article published in the Journal of Poverty and Social Justice. The definitive publisher-authenticated version of 'Three Ways to Defend Social Security in Britain' (Baumberg 2012). Journal of Poverty and Social Justice, 20:149-61, is available online at http://dx.doi.org/10.1332/175982712X652050 


\title{
Three ways to defend social security in Britain
}

\author{
Ben Baumberg, Lecturer in Sociology and Social Policy ${ }^{1}$
}

School of Social Policy, Sociology and Social Research (SSPSSR), University of Kent

b.p.baumberg@kent.ac.uk, 01227823345

Abstract: British social security is now in a time of crisis, where cuts are being made to a system that was already struggling to provide decent security. In this paper I argue that successful proposals to combat this must (i) lead to reductions in poverty/inequality; (ii) fit existing perceptions of claimant 'deservingness'; and (iii) change deservingness perceptions in the long-run. I conclude that three influential recent proposals - 'Decent Childhoods', 'National Salary Insurance', and 'The Solidarity Society' - are only partially successful in meeting these criteria, and that successful reform requires a fusion of the respective insights of each proposal.

Keywords: social security, universalism, public attitudes, institutions, inequality

\section{Introduction}

This is not just a time of crisis in the economy, but also a time of crisis in British social security. The Coalition Government is making savings through restrictions on eligibility (such as the means testing for many incapacity claimants ${ }^{1}$ after one year) and declining levels of payment (such as the change in how benefits are uprated with inflation), with greater unspecified cuts still to come (Crawford et al., 2012). Yet arguably the social security crisis pre-dates this; while children will be hit particularly badly by the current cuts, in recent years the system has increasingly struggled to provide decent security to working age adults without children. Midway through the previous Labour administration, the net replacement rate of earnings provided by unemployment benefits was $54 \%$ in Britain, compared to $70 \%$ or more in countries such as the Netherlands and Denmark (OECD 2006, cited by Cooke, 2011).

This is no accident, but instead reflects a weak - and weakening - level of public support for benefits claimants, as illustrated in Figure 1 using British Social Attitudes (BSA) data. ${ }^{2}$ In the 1980s, 70-75\% agreed that 'large numbers of people falsely claim benefits'; by the late 2000s, it was more than $85 \%$. There was an even sharper rise in the proportion feeling that 'unemployment benefits are too high and discourage work', rather than being 'too low and cause hardship'. Neither these attitudes nor these trends are universal. Whereas only $32 \%$ of Danes think that 'many people manage to

\footnotetext{
${ }^{1}$ Employment and Support Allowance (ESA) - now the main benefit for people not-working due to sickness and disability - is being time-limited to 12 months for a specific but not uncommon group: those that have made recent National Insurance contributions (hence they were on 'contributory ESA'), and who are sick/disabled enough to pass the strict medical assessment, but no so sick/disabled that they are placed in the 'support group'.

${ }^{2}$ Full documentation - including Stata code - to replicate all the BSA analyses in this paper are available from www.benbaumberg.com
} 
obtain benefits/services they are not entitled to', this is true of $77 \%$ of Britons. ${ }^{3}$ And countries such as Sweden have seen no such deterioration in public support (Svallfors, 2011).

What can be done to restore decent social security in such a climate of public distrust? Using research on deservingness, institutions, and discourses, I suggest three criteria for judging such proposals. I then apply these criteria to three recent examples that adopt widely different responses to these issues. These are also important in their own right, the first being co-authored by the editor of the current issue of this journal, the second by a former special adviser to the Labour Secretary of State for Work and Pensions, and the third by a newly-appointed adviser to the Labour leader authors fluent in both policy research and the art of politics. I ultimately argue that conditionality will be critical to any plausible solution - but that this must be a different sort of conditionality from that which dominated the New Labour years (1997-2010).

There is of course ongoing debate in political science about whether public attitudes have a critical influence on policy (e.g. Myles, 2006). While there is scope for political parties to implement unpopular policies, especially in the British political system, for the purposes of this article I assume that attitudes have a causal impact on policy, as the British Left has tended to assume in recent years (White, 2010).

Figure 1: Trends in attitudes to social security in Britain

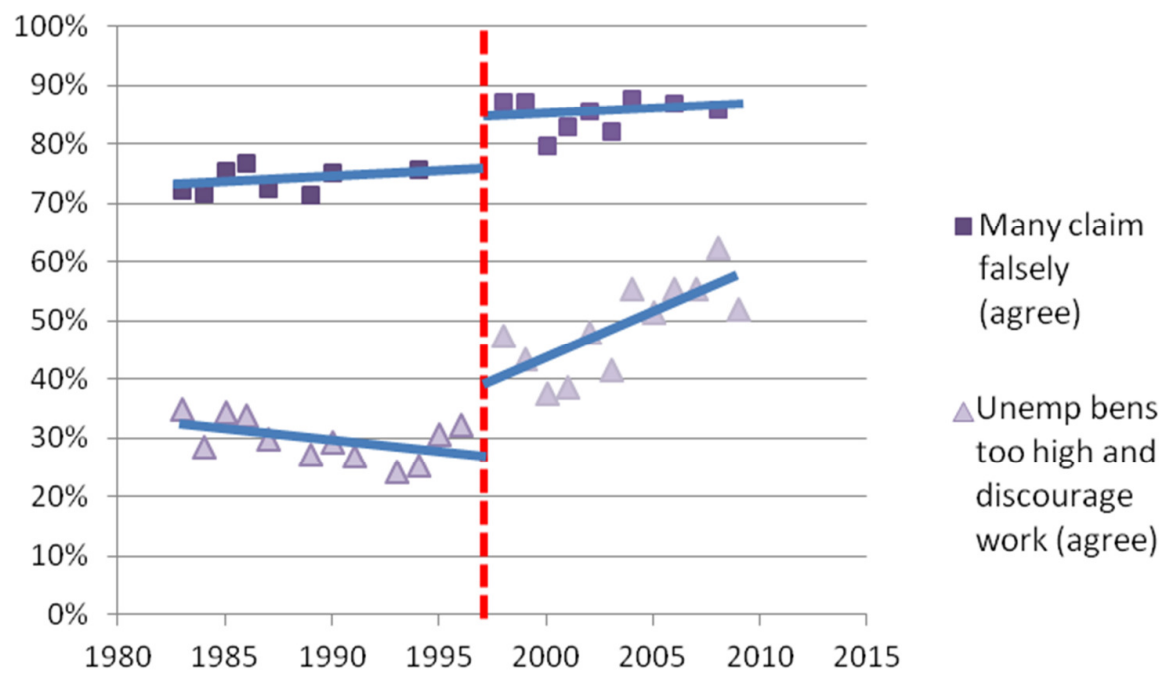

Source: author's analysis of British Social Attitudes data, accessed via the UK Data Archive (details on variables, weights etc are given in the Web Appendix).

\section{Deservingness, institutions, discourses}

To understand the strengths and weaknesses of these proposals, I begin by briefly reviewing part of the large literature on welfare states, focusing on three points of critical importance. My starting

\footnotetext{
${ }^{3}$ Weighted European Social Survey (ESS) 2008 analysis of variable 'bennent', accessed via the ESS Nesstar tabulation tool at http://nesstar.ess.nsd.uib.no/webview/
} 
point is van Oorschot's (2000) concept of 'deservingness' - that is, 'who should get what, and why'. Van Oorschot presents evidence that these views are based on five principles:

- Are you needy? (need)

- Is your neediness your own fault? (control)

- Are you one of us? (identity/solidarity)

- Are you docile and compliant? (attitude)

- What have you done, or can you do, for us? (reciprocity)

van Oorschot (2006) found that there was a universal ordering across countries such that people were most concerned about older people, followed by disabled people, then unemployed people, and finally immigrants- a pattern explained by the perceived deservingness of these different groups, particularly their perceived control, identity and reciprocity (van Oorschot, 2000). For this article, I take it that we cannot understand public attitudes without understanding public views on whether benefit claimants are deserving.

The second - and critical - point is that perceived deservingness is affected by institutional design. Many will know Titmuss' \{, 1968 \#202: 134\} aphorism: 'services for poor people have always tended to be poor quality services'. This battle of universalism against selectivity is consistently replayed, and it has widely been argued that selective welfare states lead to poorer outcomes for people in poverty: public support is lower, private provision is higher, and the total budget of the welfare state is therefore much smaller (e.g. Korpi and Palme, 1998). For the present paper, I focus on Larsen's (2008) argument that more selective welfare states - or parts of welfare states \{Horton, 2009 \#164: $108\}$ - lead to perceptions of benefit claimants as less deserving. Larsen argues (following Rothstein) that selectivity 'opens the discussion' on whether recipients are deserving, compared to universalism that 'closes' this debate. This is because selectivity by its nature draws attention to the threshold between the 'needy' and the rest, and whether this 'needy' group are themselves to blame for their situation. ${ }^{4}$

To be clear: this does not mean that there is no perception of undeservingness in more universal welfare states. As many as $50 \%$ of Swedes agree that 'many people manage to obtain benefits/services they are not entitled to', ${ }^{5}$ and - according to one unpublished working paper - that many of those who report themselves ill are not really ill (Halvorsen, 2002). Yet there is a clear difference in the extent of these attitudes between more and less universal welfare regimes, particularly for attitudes around dependency, where 37\% in Sweden think social benefits/services make people lazy, compared to $66 \%$ in the UK (see also Taylor-Gooby, 2011). Underlying attitudes are made more or less salient depending on institutional design.

The final point is that 'institutional design is not destiny' \{Schmidt, $2008 \# 189: 317\}$. Schmidt argues that the literature on institutions is too deterministic in positing one or other form of path dependence (punctuated by moments of radical change at crisis points). Instead, her account of 'discursive institutionalism' allows the possibility of elites gradually and deliberately changing discourses. However, such elites are not all-powerful, and the effects of discourses depend on a

\footnotetext{
${ }^{4}$ Larsen supplements this account with two other institutional features that are not the focus here: welfare state generosity, and the extent of job opportunities.

${ }^{5}$ ESS data; see footnote 3 .
} 
multitude of factors, including their credibility (p311). In other words, discourse matters, but must be persuasive in any given, institutionally constrained context.

In this interplay between deservingness perceptions, institutions and discourses, we must remember the temporal dimension and what Bonoli and Palier (2007) term 'sequencing'. Using the example of pensions reform in Bismarckian welfare states, they argue that change 'takes place in stages, and each stage facilitates the adoption of the next one' (p556). Putting all this together, we can accept that at some general level the British welfare state was resilient in the short term during the Thatcher period \{Pierson, 1996 \#191: 161-2\}. Yet this was also a period when the Thatcher government was successfully changing policy details and certain discourses \{Schmidt, 2008 \#189: 317; Horton, 2009 \#164: 40\}, which laid the foundation for more recent changes (although see below). Outside moments of rupture, the possibility of change is greater in the long run than the short run.

My argument here is that these three insights help us think about particular policy proposals in the British context. This is a surprisingly rare step; the welfare state literature has focused on initial expansion and more recent retrenchment \{Pierson, 1996 \#191: 143\}, but not guidance for attempts to increase welfare state generosity. From this discussion, however, I argue that successful proposals...

1. ... lead to reductions in poverty and/or inequality (the goal assumed here);

2. ... fit with existing deservingness perceptions (for political viability);

3. ... change deservingness perceptions in the long term, through revised rhetoric or institutions (to enable future, sequenced increases in generosity).

The question is thus: to what extent do the three proposals considered here fit with these criteria, and therefore offer a possible route to a more generous welfare state in Britain?

\section{Proposal \#1: Beyond Child Poverty}

For Bell and Strelitz (2011), the over-riding problem is the term 'child poverty' itself. This is not to suggest that they ignore the real successes of the child poverty agenda; in their report 'Decent Childhoods', they begin by cataloguing these successes, including a Conservative party that signed up to a relative poverty target on the eve of the 2010 election. Yet they argue that the child poverty framing was 'ultimately lacking' in its attempt to achieve Tony Blair's ambitious target to end child poverty - and this failure was on political grounds. The term itself 'did not resonate widely', and many potential supporters 'barely noticed what was going on'. This was for three reasons:

1. An over-emphasis on income: 'The ideas that motivate people to care about these issues are not only about a lack of income, but other aspects of fairness and justice.'

2. An 'us' and 'them' framing, which never got across that as many as $30 \%$ of 'us' are in poverty at some point in our lifetime.

3. What Bell and Strelitz term 'insufficient respect for those in poverty'.

The failure was therefore on the grounds of both 'politics and policy' (p28) - the inability of the term child poverty to provide the basis for the policies or popular support that would have allowed 'truly transformative' change (p13). The way out, according to Bell and Strelitz, is to move to a new 
framing: 'Decent Childhoods'. A Decent Childhood is a three-pronged ideal where 'all children live in families with financial security, all children have meaningful opportunities; and all children are valued' (p7). While not providing a detailed policy manifesto, they do set out a broad plan of action that includes getting more people into better jobs, tackling educational inequalities, and encouraging a 'shared sense of responsibility' that gets a broad base of support for such policies and ensures that politicians no longer stigmatise poor people.

There is much to admire in Bell and Strelitz's report, and much to agree with in the recommendations. And from the perspective of the three criteria put forward in this article by which to judge proposals for positive change, the suggestions are partly promising. According to the first criterion, of tackling poverty/inequality, the main focus of Decent Childhoods is on market income rather than on raising benefits (reflecting the authors' focus on families with children, for whom benefits have already been increased, although these increases will now be reversed at least in part under the current coalition government); but the ambition of the policy agenda is considerable. And the report is firmly oriented around the long-term changes in attitudes demanded by the third criterion: Decent Childhoods frames the problem as identity (the 'us' and 'them' framing) and deservingness more generally ('insufficient respect'), while a key part of the solution is a change in rhetoric to transform the perceptions of the public.

Notably, though, the authors do not talk about deservingness directly - a deliberate decision on their part (p40). Bell and Strelitz believe that challenges to the existing discourse that 'draw the line between 'deserving' and 'undeserving' recipients of welfare in a fair and just manner' will fail, and simply reinforce 'the message that poverty is primarily a result of individual failure' ( $p 42)$. Their strategy is one of talking across existing discourses on 'dependency', rather than tackling them headon, with any discussion of conditionality being entirely absent.

The problem is that such a discourse goes against the grain of public attitudes (see also below), and it is unclear what will enable this reframing to be successful. Implicitly, Decent Childhoods has a conception of public attitudes as free-floating, malleable and able to be shaped by the rhetorics of politicians on the left - the authors seemingly know that discourses are not the playthings of elites (cf. Schmidt, 2008), and choose to present a utopian vision rather than restricting themselves to political realities. Yet British institutions are structured to open up the debates that Bell and Strelitz are trying to close down. Even if 'decent childhoods' were to be adopted in the short term, without institutional supports it would seem liable to collapse in the long term.

In summary, Bell and Strelitz offer us a vision of a transformed policy agenda and a new, more supportive set of public attitudes, but do not explain how such a vision is achievable given the discursive and structural institutions that Britain faces. To use a familiar metaphor, they offer a final destination without a road map. This therefore provides one part of a possible way forward, but for the rest of the solution we turn to the other two proposals, which take very different approaches.

\section{Proposal \#2: National Salary Insurance}

'What I would love to see is Britain fall in love with welfare again.' So said former Labour Secretary of State for Work and Pensions James Purnell (in Wintour, 2011), on the release of a report by his former special adviser (Cooke, 2011), published by the think-tank Purnell now chairs (the Institute 
for Public Policy Research). Cooke's goal was to respond to the low level of unemployment benefits in Britain, in a context in which public spending is under intense pressure, and in which there is low public support driven by perceptions that contributions are unrewarded and that there are too few demands made on claimants.

Cooke's solution to this is 'National Salary Insurance' (NSI) - an additional earnings related unemployment benefit paid for six months, which would provide $70 \%$ of previous earnings up to a maximum of $£ 200$ per week. The innovative idea is that people would then pay this extra money back to the state when they got a job again, the total repayment being a maximum of $£ 3,445$, with a zero real rate of interest. Otherwise, nothing else would change; NSI would not be subject to tax or affect other benefit entitlements, and would operate with exactly the same conditions as existing unemployment benefits (Jobseekers' Allowance). And after six months, NSI would expire and people would be left on the present benefits system.

The strength of NSI lies in the second of the criteria here: in contrast to Bell and Strelitz, it is explicitly designed to fit comfortably with contemporary perceptions of deservingness. The insurance is limited to people in work and therefore both like 'us' (according to van Oorschot's principle of identity) and with a demonstrable work ethic (the principles of control and attitude), while the money will usually be paid back quickly (cementing the idea of reciprocity). Moreover, it does not involve the imposition of tax rises, or the search for cuts elsewhere, making it particularly suited to the present climate of austerity.

The success of NSI in meeting the first criterion of poverty/inequality is more mixed. It is a misnomer to call this 'insurance'; most of us would describe these payments as a 'loan', however subsidised the rate of interest is, and despite having the loan written off if we never work again. And because it is not insurance, $80-90 \%$ of the total cost would be borne by those who become unemployed and then return to work. There is something to be said for redistributing within the lifecycle of individuals, which is a much better description of the welfare state than is commonly realised (Falkingham and Hills, 1995). Yet not only would this proposed system reduce work incentives, but in practice it also means that any additional help when unemployed is followed quickly by additional struggles when working again - a short-term redistribution of struggles, rather than a redistribution from times of plenty to times of trouble.

Yet the biggest question mark is over the third criterion, of long-term attitudinal change. Purnell's quote above suggests that people could 'fall in love with welfare again'; the NSI provides meaningful protection against unemployment considerably higher than the current level, and claimants will be likely to be seen as deserving. But it is difficult to see what the next step towards a popular, generous benefits system would be. Discursively this is an acquiescence to current attitudes rather than an attempt to challenge them, which separates out 'more deserving' short-term unemployed people from those who are long-term unemployed. And institutionally 'deserving' unemployed people would not just be in a different scheme from the 'undeserving' who have not recently worked, but each individual's funds would be hypothecated for their own use. It is hard to see how people would view this as anything other than a direct loan to themselves, introducing additional barriers to more traditional risk-pooling or collective financing mechanisms.

In summary, the diagnosis of the problem is acute, and NSI creatively provides more help to the unemployed within a confined political space. Yet there seems only a remote possibility for NSI to 
provide a platform for a sequence of steps that culminate in a recast welfare state. Purnell's laudable ambition for NSI therefore seems unlikely to be borne out by Cooke's innovative proposal.

\section{Proposal \#3: The Participatory Principle}

The most sustained engagement with the conundrum of deservingness comes from Horton and Gregory's book-length The Solidarity Society (2009; hereafter TSS). ${ }^{6}$ TSS again treats public attitudes as central, arguing that poverty policies over the twentieth century 'were driven by significant shifts in public attitudes to welfare and in the underlying quality of social relations' (p.xvi). Unlike most other analyses, they explicitly continue to say that this 'was itself shaped by how the welfare institutions of the time treated people'. Indeed, the motif of the entire book is the interplay between institutions and attitudes, based on reviews of the academic literature combined with new work on contemporary public attitudes.

To reinvigorate the welfare state, the authors of TSS believe that there is a need to transform institutions, which in the long run will then transform attitudes. Critical to this is the desire to replace need with reciprocity as the centrepiece of a revitalised welfare state, based on their own research that highlights reciprocity as the most important of van Oorschot's principles. The post-war Beveridge system was focused on reciprocity, but had a narrow view of 'contribution' that excluded performing care work and which therefore particularly penalised women. TSS can be read as an attempt to rediscover Beveridge, but replacing 'contribution' with 'participation', and appropriately valuing 'socially useful work' outside the labour market - a step they label 'the participatory principle' (p212).

Fundamental to the participatory principle is conditionality. 'For public perceptions of fairness, it is important to communicate that there is a requirement to participate and a framework of conditionality in place with the possibility of sanctions' (p197-8). Yet at the same time, conditionality should only ever be used 'to help the claimant themselves', and never aimed at 'playing to public opinion'. These statements seem contradictory until we recognise that there is (in my terms) 'good conditionality' and 'bad conditionality'. While the latter is the Wisconsin workfare model, good conditionality will use sanctions as a last resort, but only ever in a 'fair and humane way' (p197), tied to generous financial support for claimants to help them back to work (p199), and matched by a state commitment to providing fair opportunities (p221).

Their second step in revitalising the welfare state is to 'universalise the system' (p216), partly through a universal tax credit - effectively a low-level basic income to replace the income tax allowance. But more important is their idea of the 'lifetime welfare contract'. People start their lives by claiming from the welfare state, through child benefits, education, and healthcare; we therefore all begin our working lives with an obligation to 'pay back' the services we have already used. In midlife we then on average become net contributors to the system, but with the knowledge that we have been net recipients in the past, and the expectation that we will be so once more in old age. In

\footnotetext{
${ }^{6}$ Like Bell and Strelitz, this was funded by the Webb Memorial Trust to commemorate the centenary of Beatrice Webb's Minority Report of the Royal Commission on the Poor Law - see www.webbmemorialtrust.org.uk.
} 
effect, Horton \& Gregory want to 'rejuvenate the classical notion of social insurance' (p216), but stretching this to involve participation rather than only contributions via paid employment (p218).

TSS is based on the same ideas underlying the three criteria above, so it should be no surprise that it is relatively successful in meeting them; it suggests a more generous welfare state, designed to entrench more progressive values in the long term. Yet concerns remain, partly around the second criterion of fit with public support, where - despite the attitudinal research underlying the analysis there are two problems. Firstly, they do not deal effectively with disability/incapacity, which is only mentioned cursorily (p68). The rhetorical power of 'participation' is in its ability to incorporate care work within van Oorschot's reciprocity - but what happens to those who are not participating because they cannot find work that their health allows them to do? Disability dominates British deservingness debates (Briant et al., 2011); and before the crisis, the public thought that as many as 37 out of every 100 sickness/disability claimants was fraudulent. ${ }^{7}$ Disability is therefore a serious omission.

Secondly, at the centre of TSS is the connection between institutions and attitudes. Yet TSS never explicitly deals with the questions of how to break out of the current symbiosis of sceptical attitudes and a highly selective welfare state. Instead, we are left to piece together various implicit clues scattered throughout the book. Occasionally the emphasis is on a lead by politicians, as when stressing the need for 'a major shift in our public culture of welfare: in how people view it and those claiming it, and in how our politicians talk about it' (p222). But primarily the emphasis is on institutions: a participatory principle that chimes with the public's criteria of deservingness, and a reuniversalised welfare state that in the long term will '[secure] middle-class "buy-in"' (p174) and change the entire debate around deservingness. The assumption is that it is possible in a single sweep to make these changes while still maintaining popular legitimacy - when the alternative of a sequenced approach to change is more realistic.

Despite these limitations around disability and timing, though, TSS represents a significant - and essential - contribution to debate.

\section{Discussion}

In this article, I have assessed three proposals for policy reform against three criteria of (i) reducing poverty/inequality; (ii) fitting existing public perceptions of deservingness; and (iii) changing future public perceptions of deservingness. In bringing these together, I want to use TSS as my point of departure, as it takes most seriously the need to link institutional and attitudinal change. But beyond this, I want to demonstrate how the proposals of Cooke and Bell/Strelitz offer additional insights into possible ways forward.

Firstly, Cooke's NSI epitomises the art of the possible: it reduces poverty - a little (thus meeting the first criterion), and shapes itself to public attitudes (meeting the second criterion), but does this without trying to transform attitudes, and therefore fails the third criterion put forward here. In so doing, it highlights a problem in TSS: Horton \& Gregory propose an ambitious agenda to genuinely

\footnotetext{
${ }^{7}$ Author's analysis of BSA 2007 data, accessed via the UK Data Archive (details on variables, weights etc are given in the Web Appendix).
} 
transform attitudes, but this only partially fits itself to existing debates around deservingness. If we could reconceive TSS as a series of steps that each open up new vistas of action, then it becomes easier to visualise a path to the final TSS goal. The initial step would have all of the features of NSI, except that it would be designed to increase - rather than restrict - the scope for future action.

Secondly, we must take seriously Bell and Strelitz's warnings over the dangers of engaging in the deservingness debate and its long-term implications for public attitudes: the path of conditionality treads a tightrope from which Labour has tended to fall the wrong side. TSS makes a clear distinction between good and bad conditionality, arguing that New Labour's conditionality not only contained elements that genuinely helped claimants but 'could also have been used to restore confidence in the integrity of the system. Sadly, however, these developments have been accompanied by a narrative about "cracking down" and "targeting benefit thieves" that has actually reinforced people's concerns about the integrity of the system' (p210).

The evidence for the counterproductive role of conditionality may not be definitive, but it does seem persuasive. Rather than a consistent deterioration in support for the welfare state, Figure 1 suggests a discontinuity at the point that New Labour was elected. Moreover, the decline in support for the welfare state has been primarily among Labour voters since 1997 (White, 2010:26). The first signs of this came in Hills \{, $2001 \# 194: 25\}$, who found that the biggest decline between 1996 and 1998 and the biggest recovery between 1998 and 2000 in support for higher unemployment benefits was among Labour identifiers. More recently, Sefton \{, $2009 \# 201: 240\}$ showed that the hardening of many inequality-related attitudes was much greater among Labour supporters than Tory supporters. Using the same data, but focusing on the belief that large numbers of people falsely claim benefits, ${ }^{8}$ I find that Labour identifiers were $12 \%$ more positive than non-Labour identifiers from 1983 to 1994, but only $6 \%$ more positive between 1998 and 2008. Similarly, the Labour vs. non-Labour gap for believing that unemployment benefits are too low and cause hardship was $27 \%$ before 1997 and $11 \%$ after 1997.

We should bear in mind that changes in attitudes were seen to some extent among voters of all persuasions and were seen across a range of inequality-related attitudes rather than limited to perceptions of deservingness (Sefton, 2009), and that it was values (related to redistribution) rather than perceptions (of fraud) that most seemed to explaining changing support for welfare spending (Taylor-Gooby and Martin, 2008:249). Still, these are hardly grounds for seeing benefits conditionality as a success in restoring public confidence in the benefits system.

It is therefore disturbing that the message of TSS is increasingly being taken to be the need for conditionality and reciprocity. Aside from Labour's Shadow Work and Pensions Secretary's response to NSI (Wintour, 2011), the speech of the Labour leader, Ed Miliband, on responsibility (13 ${ }^{\text {th }}$ June $2011)^{9}$ began with an anecdote about the undeserving incapacity benefits claimant as an example of the irresponsible society, stating that 'we will be a party that rewards contribution, not worklessness'. This was followed by an enthusiastic write-up of the emphasis on conditionality by Horton himself (2011) - and a matter of months later, Horton was given a job in Ed Miliband's advisory team. This is all close in tone to the stated intention of the (then newly-elected) Labour

\footnotetext{
${ }^{8}$ BSA data; further details available from the Web Appendix at www.benbaumberg.com

${ }^{9}$ http://www.politics.co.uk/comment-analysis/2011/06/13/ed-miliband-responsibility-speech-in-full [accessed 4/11/2011]
} 
Prime Minister Tony Blair in the late 1990s when he was setting out his commitment to end child poverty in a generation (Blair, 1999). Again, this speech emphasised conditionality - but it began: 'Today I want to talk to you about a great challenge: how we make the welfare state popular again'.

The challenge is thus that a discourse that ignores deservingness will not chime with public attitudes, while a discourse that simply accommodates attitudes will struggle to transform them. The path to a revitalised benefits system that reduces poverty instead seems likely to consist of a series of stages that both respond to public concerns and offer the potential for sequenced change. The proposals in TSS, in particular those around 'good' conditionality, are promising but difficult, and there is a temptation for the message to be simplified back to the existing status quo on the importance of 'bad conditionality'. As White puts it (White, 2010:26), 'once the issue of reciprocity becomes simply, or even primarily, a question of how tough to get with welfare recipients, the left has already lost the battle'.

It is necessary to end by facing the dire financial situation. In the short term, the scope for increasing benefits payments and universalism is limited, and the temptation for those on the left is to accept greater levels of means testing in order for scarce funds to be directed to those in acute need. Yet we know that in the long term this is at the price of wider solidarity and support, and will result in claimants being seen as even less deserving than they already are. What is needed is a way of deciding (i) where universalism is particularly important for perceptions of deservingness and solidarity; and (ii) what short-term decisions can be taken that allow the greatest space for the future rebuilding of the welfare state. The proposals here offer some suggestions, then, but there remains much intellectual work to be done.

\section{Acknowledgements}

Many thanks to the National Centre for Social Research for creating and depositing BSA data at the UK Data Archive, and to Norwegian Social Science Data Services for access to ESS data (and also to the innumerable funders of both surveys); in both cases copyright remains with the data depositors. Particular thanks are due to Trude Sundberg, as well as the editor and two anonymous referees (with the usual caveats that none of these should be held responsible for the interpretations in this article).

\section{References}

Bell, K., and Strelitz, J. (2011) 'Decent childhoods: Reframing the fight to end child poverty', Newcastle: Webb Memorial Trust.

Blair, T. (1999) 'Beveridge revisited: A welfare state for the 21st century', in R. Walker (ed) Ending child poverty, London: Policy Press.

Bonoli, G., and Palier, B. (2007) 'When past reforms open new opportunities: Comparing old-age insurance reforms in bismarckian welfare systems', Social Policy and Administration, 41:55573.

Briant, E., Watson, N., and Philo, G. (2011) 'Bad news for disabled people: How the newspapers are reporting disability', Glasgow: Strathclyde Centre for Disability Research and Glasgow Media Unit in association with Inclusion London. 
Cooke, G. (2011) 'National salary insurance: Reforming the welfare state to provide real protection', London: Institute for Public Policy Research.

Crawford, J. O., Emerson, C., and Tetlow, G. (2012) 'Fiscal repair: Painful but necessary', in C. Emerson, P. Johnson and H. Miller (eds) The ifs green budget: February 2012, London: Institute for Fiscal Studies (IFS).

Falkingham, J., and Hills, J. (eds). (1995) The dynamic of welfare: The welfare state and the lifecycle, London: Prentice Hall.

Halvorsen, K. (2002) 'Solidarity and the legitimacy of the welfare state: Attitudes to abuse of welfare benefits in the scandinavian countries', COST A13 Project meeting "Changing labour markets, welfare policies and citizenship', Florence, 31/5/2002-1/6/2002.

Hills, J. (2001) 'Poverty and social security: What rights? Whose responsibilities?', p1-28 in A. Park, J. Curtice, K. Thomson, L. Jarvis and C. Bromley (eds) British social attitudes: The 18th report, London: SAGE publications in association with the National Centre for Social Research.

Horton, T. (2011) 'Ed Miliband's speech hits the right note on welfare responsibility', The Guardian 13/6/2011: http://www.guardian.co.uk/commentisfree/2011/jun/13/ed-miliband-speechwelfare-responsiblity.

Horton, T., and Gregory, J. (2009) The solidarity society, London: Fabian Society.

Korpi, W., and Palme, J. (1998) 'The paradox of redistribution and strategies of equality: Welfare state institutions, inequality, and poverty in the western countries', American Sociological Review, 63:661-87.

Larsen, C. A. (2008) 'The institutional logic of welfare attitudes: How welfare regimes influence public support', Comparative Political Studies, 41:145.

Myles, J. (2006) 'Comment on brooks and manza, asr, june 2006: Welfare states and public opinion', American Sociological Review, 71:495-98.

Pierson, P. (1996) 'The new politics of the welfare state', World Politics, 48:143-79.

Schmidt, V. A. (2008) 'Discursive institutionalism: The explanatory power of ideas and discourse', Annual Review of Political Science, 11:303-26.

Sefton, T. (2009) 'Moving in the right direction? Public attitudes to poverty, inequality and redistribution', p223-44 in J. Hills, T. Sefton and K. Stewart (eds) Towards a more equal society? Poverty, inequality and policy since 1997, Bristol: Policy Press.

Svallfors, S. (2011) 'A bedrock of support? Trends in welfare state attitudes in sweden, 1981-2010', Social Policy and Administration, 45:806-25.

Taylor-Gooby, P. (2011) 'Opportunity and solidarity', Journal of Social Policy, 40:453-570.

Taylor-Gooby, P., and Martin, R. (2008) 'Trends in sympathy for the poor', in A. Park, J. Curtice, K. Thomson, M. Phillips, M. Johnson and E. Clery (eds) British social attitudes 2007-2008: The 24th report, London: National Centre for Social Research.

Titmuss, R. (1968) Commitment to welfare, London: Allen \& Unwin.

van Oorschot, W. (2006) 'Making the difference in social europe: Deservingness perceptions among citizens of european welfare states', Journal of European Social Policy, 16:23-42.

- - - (2000) 'Who should get what, and why? On deservingness criteria and the conditionality of solidarity among the public', Policy \& Politics, 28:33-48.

White, S. (2010) 'The left and reciprocity', Soundings, 46:18-30.

Wintour, P. (2011) 'James purnell looks to reinvent welfare state with salary insurance', The Guardian 27/7/2011. 